\title{
Advancement of Nanomedicine and Targeted Drug Delivery in Perspective of Liver Disease
}

\author{
Mohammad Firoz Alam* \\ Neuroscience and Toxicology Unit, Pharmacology \& Toxicology Department, Pharmacy College, Kingdom of Saudi Arabia
}

Submission: March 12, 2018; Published: May 11, 2018

"Corresponding author: Mohammad Firoz Alam, Assistant Professor, Department of Pharmacology and Toxicology, College of Pharmacy, Jazan University Jazan, Post box 114, Kingdom of Saudi Arabia, Email: firozalam309@gmail.com

\begin{abstract}
Unhealthy life style such as consumption of alcohol, drug, chemicals, cigarette, unhealthy eating, various biological infections and lack of physical activity is a major factor to increase the disease burden on the liver. There are more than hundred different kinds of liver diseases, some of them is serious and life threatening such as liver cancer. Nanomedicne is playing very effective an alternative potential agent to overcome the liver diseases by targeting the different pathway, such as hepatocytes, macrophages, receptor, intracellular molecular network and hepatocellular carcinoma. There are very few Nanomedicine is available in the market and fews are under a clinical trial to treat the various liver problem. Therefore, there is further need to focus and explore the variety of Nanomedicine to treat the liver diseases including the liver cancer.
\end{abstract}

Keywords: Nanomedicine; Liver diseases; Oxidative stress; Inflammatory cytokine

\section{Introduction}

The liver is the largest solid organ of the body that have multi-function in which some is the very important such as metabolism and detoxification of xenobiotics [1,2]. Every day we are exposed to various toxic chemicals intentionally or unintentionally by breathing air, drinking water, eating food or drug etc and increasing the chemical burden on the human body especially for the liver. Plastic, chemicals, drugs and lifestyle certainly responsible for increase the burden of liver [3]. In the Fourth National Report on Human exposure to environmental chemicals, the Centre for Disease control(CDC) USA reported that the average person in the USA has at least 212 chemicals in their blood and urine that actively contribute the chemical burden on the body [4]. Thus, our lifestyle is directly or indirectly responsible to increase the liver disease burden in human body. Our body has a self-cleansing mechanism which helps to clear the burden of xenobiotics from the body by detoxification process, but the continuous exposure of drug/chemical lead to accumulation and resulted in variety of liver problem [5]. In spite of that chemical, drug or some biological infection such as bacterial, viral, parasitic also responsible for severe liver diseases [6]. There are more than hundred different kinds of liver diseases, some of them is serious and life threatening such as liver cancer. The current scenario of liver diseases prospect throughout the globe is that millions of people suffering from the variety of liver diseases from childhood to old age. Some important liver diseases such as viral hepatitis, liver cirrhosis and hepatocellular carcinoma is global health challenges due to the limited curative treatment options [7]. Therefore, there is need to develop a safe and potent target drug to overcome the liver problem. Thus, Nanomedicine can be a good option to contribute the potential effect towards the targeted delivery of hepatic diseases.

\section{Discussion}

The application of nanoparticle has been emerging as a potential, delivering targeted drugs to treat various liver diseases [8]. Advancement of nanotechnology has been open a new gateway to improve the targeted and delivery of drug to treat the various diseases. Present review design to focus and understand the effect of Nanomedicine in perspective of liver diseases specially hepatocellular carcinoma [9]. The advancement of Nanomedicine will helps to improve the therapeutic index of anticancer drug via modulation of pharmacokinetics and tissue distribution to targeted delivery [10]. Nanomedicine can be easily targeted to the hepatocytes in case in viral, fungal, bacterial, parasitic infection of liver diseases [11,12]. It also may be targeted as macrophages, hepatocellular carcinoma. Therefore, the Nanomedicine attracting the scientific community to think and continue the research to overcome with the different kind of diseases. Now the updated progress in this field is that some of Nanomedicines are in clinical trial phase while some are already available in the market with a different brand name. The first 
liposomal doxorubicin (Doxil TM /Caelyx Tm) was the first anti cancer Nanomedicine approved by the FDA in 1995. The other Nanomedicine named Irinotecan brand Onivyde Merrimack Pharmaceuticals is approved for the use of pancreatic cancer while some of the nano drug such as Doxorubicine brand Therm DoxTM/Celsion can used as primary hepatocellular carcinoma which is under final trial. A drug named Oxaliplatin brand name MBP-426/Mebiopharm is also under the clinical trial of phase -II which will be used for gastrointestinal adenocarcinoma. Thus the Nanomedicine is effective to over the liver disease.

\section{Conclusion}

The Nanomedicine is an exciting and promising field of research for the treatment of liver diseases and it can be contributed significant role towards the targeted delivery of various hepatic diseases. There is further need to continue the research to find out the more economical, suitable and safer Nanomedicine to fight the various kinds of liver problem.

\section{References}

1. Crispe IN (2009) The liver as a lymphoid organ. Annu Rev Immunol 27: $147-163$.

2. Safhi MM, Alam MF, Khuwaja G, Islam F, Hussain S, et al. (2016) Repeated Exposure of sodium tellurite on the rat liver and on the potential mechanisms of the metalloid-induced hepatotoxicity. Acta Pol Pharm 5(73): 675-682.
3. Koch HM, Calafat AM (2009) Human body burdens of chemicals used in plastic manufacture. Philos Trans R Soc Lond B Biol Sci 364(1526): 2063-2078.

4. Centers for Disease Control. National Report on Human Exposure to Environmental Chemicals.

5. Pandit A, Sachdeva T, Bafna P (2012) Drug-induced hepatotoxicity: a review. J Appl Pharm Sci 02: 233-243.

6. Talwani R, Gilliam BL, Howell C (2011) Infectious diseases and the liver. Clin Liver Dis. Clin Liver Dis 15(1): 111-130.

7. Peter B (2014) The global burden of liver disease: a challenge for methods and for public health. BMC Med 12: 159.

8. Duncan R, Gaspar R (2011) Nanomedicine(s) under the microscope. Mol Pharm 8(6): 2101-2141.

9. Blanco E, Shen H, Ferrari M (2015) Principles of nanoparticle design for overcoming biological barriers to drug delivery. Nat Biotechnol 33(9): 941-951.

10. Prabhakar U, Maeda H, Jain RK, Sevick-Muraca EM, Zamboni W, et al. (2013) Challenges and key considerations of the enhanced permeability and retention effect for Nanomedicine drug delivery in oncology. Cancer Res 73(8): 2412-2417.

11. Sivakumar SM (2016) Therapeutic potential of chitosan nanoparticles as antibiotic delivery system: challenges to treat multiple drug resistance. Asian Journal of Pharmaceutics 10(2): S62.

12. Etheridge ML, Campbell SA, Erdman AG, Haynes CL, Wolf SM, et al. (2013) The big picture on nanomedicine: the state of investigational and approved nanomedicine products. Nanomedicine 9(1): 1-14.

\section{Your next submission with JuniperPublishers will reach you the below assets}

- Quality Editorial service

- Swift Peer Review

- Reprints availability

- E-prints Service

- Manuscript Podcast for convenient understanding

- Global attainment for your research

- Manuscript accessibility in different formats

( Pdf, E-pub, Full Text, audio)

- Unceasing customer service

Track the below URL for one-step submission https://juniperpublishers.com/online-submission.php 